\title{
Response to Heterologous Leishmanins in Cutaneous Leishmaniasis in Nigeria - Discovery of a New Focus
}

Simon M Agwale/ ${ }^{+}$, Dockha D Duhlinska, Gabriel Grimaldi Jr*

Department of Zoology, University of Jos, P.M.B. 2084, Jos, Plateau State, Nigeria "Departamento Imunologia, Instituto Oswaldo Cruz, Av. Brasil 4365, 21045-900 Rio de Janeiro, RJ, Brasil

A pilot study was undertaken to preliminary illustrate the leishmanin skin test (LST) positivity to distinct antigen preparations (derived from promastigote of either Leishmania major or L. amazonensis, or pooled $\mathrm{L}$. mexicana, $\mathrm{L}$. amazonensis and $\mathrm{L}$. guyanensis) in cutaneous leishmaniasis $(C L)$ patients and healthy subjects living in two endemic foci in Nigeria. The study was designed to provide insights

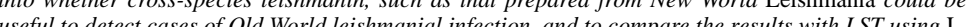
major-derived leishmanin. The overall LST position in and

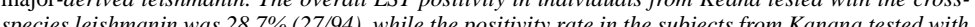
the same leishman was $54.5 \%$ (6/11). Lower positivity values were obtained when $\mathrm{L}$ major $(12.5 \%$; 11/88) or L amazons $(15.8 \%$; 9157) was tested as antigen in grossly comparable poputhions. Moreover the pooled leishmanin identified most of the subjects (13/14; 92.9\%) with active or healed CL and the maximum reaction sizes were found among positive subjects in this group. No healthy con $C$, and the maxl) showed specific DTH response. The LST was useful for assessing the prevalence of subclinical total) showed specific DTH response. The LST was useful for assessing the prevalence of subclinical in Kanana village of Langtang South local government area of Plateau State.

Key words: leishmaniasis - cutaneous leishmaniasis - Leishmania major - immunoprevalence - Nigeria

Cutaneous leishmaniasis (CL) has been obthe population of northern Nigeria by a Hall 1944, Jelliffe 1955, McMillan 1957). Despite the presence of $\mathrm{C}$ ormation is available on the epidemiology of the disease. Until the discovery of Keana village in central Nigeria as an endemic focus of CL (Agwale et al. 1993), leishmaniasis was thought to extend from northern Nigeria to the north, between $10^{\circ} \mathrm{N}$ and $17^{\circ} \mathrm{N}$ and probably much further (Jelliffe 1955 , Obasi 1991)

The LST, which measures the cutaneous delayed-type hypersensitivity (DTH) reaction to Leishmania-derived antigens, is an important tool in the epidemiological study of leishmaniasis. In

Financial support from the UNDP/WORLD BANK/ WHO special program for Research and Training in ment for the award of a Ph D degree to SM Agwale by the University of Jos, Nigeria

TWAS/CNPq fellowship and corresponding author

Fax: 234-73-56370
Received 13 January 1997
Accepted 17 September 1997

Received 13 January 1997 the appearance of the lesion and may remain posiive for life (Furtado 1980, Manson-Bahr 1987). Moreover, specific LST reactivity has often been-

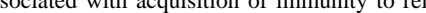
pection and skin test cross reactivity is usually paralled by comparable cross immunity (reviewed Bryceson 1976, Grimaldi \& Tesh 1993).

$\mathrm{T}$ cell responses correlate with recovery from and resistance to human leishmaniasis, thus a positive LST associated with protection might be valuable tool for evaluating vaccine trials. Periodic boosting in humans using inactivated parasites promotes a DTH response to leishmanial antigen, which seems to increase the recipient's chance of being protected (Mayrink et al. 1979, Castés et al. 1994). At present, however, there is no standardzed antigen preparation available for the determnation or DTH response in leishmaniasis patients, a w w (reviewed in Grimaldi 1995).

ned to illustrate the ine preserig tined to illustrate

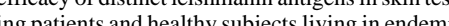
foci (which primarily involved school arls ing in Keana village), in orer to obtan inferstion on some epidemiological features of CL Nigeria. This paper also reports, for the first ime, 
the occurrence of $\mathrm{CL}$ in Kanana village of Langtang south local government area of Plateau State.

\section{MATERIALS AND METHODS}

Study sites - The study was carried out in northcentral Plateau. The Jos Plateau, situated in the southeast area of the north-central Plateau, is approximately 170 by $90 \mathrm{~km}$ in extent; except for the Shere hills $(1,800 \mathrm{~m})$, the average elevation is about $1,400 \mathrm{~m}$. It is dominated by granites and volcanic rocks. Keana village, the major area studied, situated about $262 \mathrm{~km}$ southwest of Jos $\left(8^{\circ} 40^{\prime} \mathrm{N}\right.$ and $\left.9^{\circ} 44^{\prime} \mathrm{E}\right)$, the capital of Plateau State. Its vegetation is generally Guinea Savannah, which consists of tall grasses and some trees. The annual rainfall of the zone is about $150 \mathrm{~cm}$ and lasts between 6 and 8 months. The population in Keana is about 10,000 people.

Kanana village, a new focus of $\mathrm{CL}$, is situate about $220 \mathrm{~km}$ southwest of Jos $\left(8^{\circ} 37^{\prime} \mathrm{N}\right.$ an $\left.9^{\circ} 44^{\prime} \mathrm{E}\right)$. Its vegetation is also generally Guinea savannah. It is a separate focus from Keana and the two villages are about $350 \mathrm{~km}$ apart. The population in Kanana is about 1,000 people.

Study population - The three instances in whic different leishmanin antigens were used to test schoolgirls were performed in different individuals from the same school community.

Study 1 (1995) in Keana (using the poole leishmanin), consisted of 83 schoolgirls (5 with active cutaneous lesions, 7 with scars and 7 healthy), 6 teachers ( 2 with active lesions, 1 with scars, 3 healthy) and 5 health workers $(\mathrm{n}=94)$. I addition, two persons (the principal investigato and his colleague) were tested as "negative controls". Furthermore, 11 individuals ( 2 with active lesions and 9 healthy) from Kanana village were tion in this locality. in in this locality.

Study 2 (1996) in Keana (using L. majorderived leishmanin), consisted of 4 schoolgirls with active lesions, 5 with scars and 79 healthy tive cont" were 4 students from Jos who "Ne vere lived in the endenic lishmian foc of Nigeria.

Study 3 (1996) in Keana (using L. amazonensisderived leishmanin), consisted of 2 schoolgirl with active lesions, 6 with scars and 49 heathy residents $(\mathrm{n}=57$ ). Again 4 students from Jos were selected as "negative controls".

Clinical and laboratory diagnoses - Suspected eishmaniasis cases were seen by the collaborating health centre in Keana. Also during an active search of the prevalence of $C L$ in Nigeria active lesions were seen in a 25 year old girl who was born and lives in the village of Kanana, Langtang South local government area of Plateau State. After sectional survey was carried out in discover more cases of leishmanial infection in the local population. Data regarding age, sex, dura tion of living in the locality and of infection (fo individuals with lesions or and of infection (for Diagnosis was based on microscopic deted f amastigotes in lesion biopsy smears, and/or isolation of the parasite in culture media, a positive LST, and clinical appearance of the lesions. In order to identify the causative agent(s) of CL in these villages, an attempt was made to isolate $L$ these nia from 6 human cases ( 5 and 1 patients with lesions in Keana and Kanana villages, respectively). The primary isolation was made by in vitro culturing of samples from the cutaneous lesions of turing of samples from the cutaneous lesions of fragments of lesions from patients with CL. Th material from the animals was obtained by aspiration and inoculated, aseptically, directly into tubes of NNN blood-agar medium overlaid with either Schneider's Drosophila medium (Gibco) (Hendricks et al. 1978) supplemented with $20 \%$ heat-inactivated foetal bovine serum (FBS) o RPMI 1640 (Gibco) supplemented with either 4\% FBS or $20 \%$ FCS as overlay.

Leishmanin skin test - The leishmanin antigen used for skin testing of the local population were prepared at (1) the Oswaldo Cruz Foundation/ Fiocruz, Rio de Janeiro, Brazil (consisting of pooled heat-killed L. mexicana, L. amazonensis an L. guyanensis promastigotes suspended in PBS with $0.5 \%$ phenol), (2) the Federal University of Minas Gerais/UFMG, Belo Horizonte, Brazil (heatkilled $L$. amazonensis promastigotes), and (3) the Institute Pasteur, Tehran, Iran (L. major-derived antigens). Patients and controls in study 1 were tested with leishmanin (Lot number 05111194) from Fiocruz (which was a generous gift from D AG Ferreira, Biomanguinhos). The leishmani derived from L. major (Lot number 110) and from L. amazonensis, which were employed in studie 2 and 3, were gifts from Dr F Modabber (Tropical Diseases Research, World Health Organization, Geneva, Switzerland) and Dr W Mayrink (Instite of Biological Sciences/UFMG), respectively.

All skin test antigens were administered in dose of $0.1 \mathrm{ml}$ intracutaneously on the deltoid are of the left arm. The tests (reactions measured a skin indurations) were read after 48 or $72 \mathrm{hr}$ using the ball-point pen method (Sokal 1975). An average induration diametre of equal or more than 5 $\mathrm{mm}$ was considered as a positive leishmanin test.

RESULTS

TABLE

Skin test response to the pooled leishmanin (study 1) - The positivity rate in the 83 schoolgirls (ested win this leish with active lesions, 6/7 with scars and 10/71 "healthy volunteers")

Most of the schoolgirl subjects (11/12; $91.6 \%)$ with active or healed cutaneous lesions tested were positive, although there was considerable variation pive tive response to the poled leishanin, but spe71) of schoolgirls without history of CL. Several clinical types of the disease were recognized in the local population. The lesions were ulcerative nodulo-ulcerative, and nodular, which are consistent with the clinical features of $\mathrm{CL}$ due to $L$ major (Griffiths 1987). In addition, BALB/c mice developed nodular lesions after one month of inoculation with one of the six clinical specimens studied.

Figure shows the distribution of extent of reaction to leishmanin among the positive schoolgirls in Keana village observed in study 1 . The results of skin tests analyzed according to duration of living in the focus is also reported (Table). Since the testing concentrated on schoolgirls, the results of other groups of individuals were not included in the illustrations, which refer only to study 1 . Of the skin-tested school teachers ( 2 with active lesions, 1 with scars, 3 "healthy"), 50\% (3/6) responded positively to the same leishmanin, with mean diameter of $14.5 \mathrm{~mm}, 24 \mathrm{~mm}$, and $25 \mathrm{~mm}$ respectively. Moreover, $40 \%(2 / 5)$ health workparticipated in the study $17.5 \mathrm{~mm}$ and $32 \mathrm{~mm}$

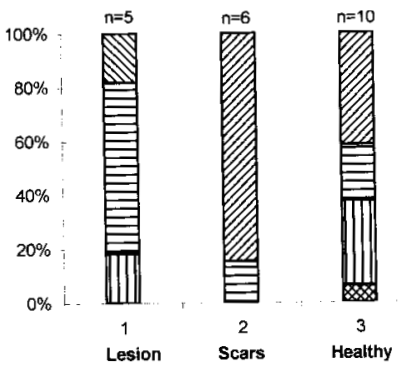

\$5:
Response to the leishmanin ${ }^{a}$ skin test in schoolgirl the time of residency in Keana village, Nigeria (Study 1)

\begin{tabular}{lcc}
\hline $\begin{array}{l}\text { Duration of } \\
\text { residency in the } \\
\text { focus (months) }\end{array}$ & $\begin{array}{c}\text { No. tested } \\
(\%)^{b}\end{array}$ & $\begin{array}{c}\text { No. positive } \\
(\%)^{c}\end{array}$ \\
\hline$<10$ & $4(4.8$ & $1(4.8)$ \\
$11-20$ & $14(16.9)$ & 0 \\
$21-30$ & $12(14.5)$ & $1(4.8)$ \\
$31-40$ & $1(1.2)$ & 0 \\
$>40$ & $52(62.7)$ & $19(90.5)$ \\
\hline Total & $83(100.0)$ & $21(100.0)$ \\
\hline
\end{tabular}

$a$ : the leishmanin antigens used for skin testing of the local population consisted of pooled heal-killed Leishmania mexicana, L. amazonensis and L. guyanensis persen those in the duration group.

In Kanana village (new focus of $\mathrm{CL}$ ), 11 subjects (2 with CL and 9 healthy) were selected for skin testing with the pooled leishmanin, of whom $6(54.5 \%)$ were positive (with an induration diameter of $13-43 \mathrm{~mm}$ ).

Attempts at isolation of Leishmania (by in vitro culturing tissue homogenates in biphasic media) made in 6 cases ( 5 from Keana and 1 from Kanana) was succesful in only one patient with an active cutaneous lesion from Kanana (who showed the maximum reaction size among the positive subjects) but the parasites were not identified.

Skin test response to L. major-derived leishmanin (study 2) - The positivity rate in the schoolgirls tested with the L. major-derived antigens in Keana (1996) was $12.5 \%$ (11/88; $2 / 4$ with active lesions, $1 / 5$ with scars and $8 / 79$ healthy), with an induration diameter of 8-53 $\mathrm{mm}$. The 4 healthy controls showed no specific DTH response. Skin test response to L. amazonensis-derived leishmanin (study 3 ) - The positivity rate in school-

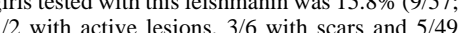
thy), with an indution dian in healthy controls showed no specific DTH response.

\section{DISCUSSION}

The indirect methods currently in use for diagnosing leishmanial infection are based on several serologic techniques, including ELISA, direct agglutination test, immunofluorescence, and immunoblot, which detect anti-Leishmania antibodies (reviewed in Grimaldi \& Tesh 1993). The LST (Montenegro test) is still frequently used for clinical diagnosis of the disease and in epidemio-
Grading of LST responses in schoolgirls $(n=83)$ among positive responses $(\mathrm{n}=21$ by clinical picture (Study 1$)$. Grade $1=$
LSt size $5-10 \mathrm{~mm}, 2=11-20 \mathrm{~mm}, 3=21-30 \mathrm{~mm}, 4=31-40$ LSt size $5-10 \mathrm{~mm}, 2=$
$\mathrm{mm}$, and $5=>40 \mathrm{~mm}$. 
logical surveys on the prevalence of leishmania dardized antigen preprower, there is no stantermination of DTH responses in leishmaniepatients, and whole killed promastigotes are still patients, and whole killed promastigotes are still
used. The high sensitivity obtained using whole used. The high sensitivity obtained using whole promastigotes in the measurement of DTH re-
sponse to leishmanial antigens continues to make sponse to leishmanial antigens continues to make
the LST a widely used technique for assessment of leishmanial infection (Bryceson 1976, Furtado 1980, Manson-Bahr 1987). As immunologic techniques are refined and as highly specific antigen become available, they may prove useful in the development of improved skin tests (Badaró et al. 1990, Weigle et al. 1991) and serological assays (Jaffe \& Zalis 1988, Andrade et al. 1992, Burns et al. 1993, Shreffler et al. 1993) for clinical diagnosis and epidemiological surveys.

Vaccination may prove to be the easiest an most effective intervention method for the prevention of leishmaniasis at a population level, but prophylatic immunization using killed promastigote vaccines is currently only in experimental stages (Modabber 1990, Grimaldi 1995). ADTH response manifested as a positive LST, which correlates with protection (Mayrink et al. 1979, Castés et al. 1994), might be a valuable tool for evaluating vaccine trials. Therefore, standardized antigens are desirable and testing the quality of commercially available leishmanin preparations in different areas of the World is important, because of the widespread use f the skin test.

In this study we have compared three differen preparations of leishmanin in two endemic foci of lew Wond Leisheriat effective for detecting Old Word CL in has This is in deement with the findings of Akufo al (1995) where jor was whe aethiopica or $L$ braziliensis. In addition, in term of sensitivity, the pooled heat-killed $L$ mexican $L$ amazonensis, and $L$ guyanensis promastigotes was apparently superior to both the other products (L. major or $L$ amazonensis-derived leishmanin) The Fiocruz mixed leishmanin is produced in ad equate quantities on a regular basis, and is available on request to other workers. An explanatio for these differences could be antigen related or due to the fact that the heterologous leishmanin were tested in roughly comparable populations of but different schoolgirls from the same school community in Keana. Comparison of these and previous studies in which skin testing was used is difficult because of the lack of uniformity in type inoculation site and dose of antigen used (Zijlstra \& El-Hassan 1993).
The LST allows one to estimate the extent of contact with the parasite and to detect cryptic infections (Pampiglione et al 1975, Kadaro et al. 1993, Marty et al. 1994). The schoolgirls in Kean village who reacted positively to the leishmanin $(14.1 \% ; 10 / 71)$, without evidence past or active CL probably indicate a subclinical infection. Most reactions were probably induced by subclinical leishmanial infection (Badaró et al 1986). Two normal controls from nonendemic areas and not known to have been exposed to leishmaniasis were skin tested with the same leishmani preparation and did not respond. The individuals with history of $\mathrm{CL}$ who were leishmanin negative (studies 1-3) may not as yet have been sensitized or, otherwise, these could be due to false-negative test results (Kadaro et al. 1993).

The distribution of positive subjects according to duration of living in the focus indicated the occurrence of continuing transmission at a relatively high rate. Asymptomatic human leishmaniasis cases (Schaefer et al. 1995), in particular reactivation of Leishmania infections in individuals infected with the human immunodeficiency virus (Alvar et al. 1992) could play a role in transmisVL Xenodiagnosis of subclinical cases and cured lish their role been suggested in order to estab(Sche (Schaefer et al. 1995). This procedure is also rectropic Leishmania spp. may occur (Gradoni et al. 1990).

In conclusion, as reported in another study (Akuflo et al. 1995), our data indicate that there is enough cross-reactivity between Leishmania speleishmenin a of leishmaniasis in endemic foci. Our study log of leish an also the prevalence of subclinical infection and for measuring $C L$ trans

\section{CKNOWLEDGEMENTS}

To the Village Heads for their co-operation throughout the study. To Mr J Sule, Mr B Dondji and Mr G Ng for help during field work.

\section{REFERENCES}

Agwale SM, Dondji B, Okolo CJ, Duhlinska DD 1993. Clinical and parasitological prevalence of leishmaPlateau State, Nigerian Mem Inst Oswaldo Gruz 88 . 347

kuffo H, Darce M, Maasho K, Berhan TY 1995. In vivo evaluation of immune responses in leishmaniasis: The use of cross-species leishmanin prepara-
tions for skin testing. Am J Trop Med Hyg 53: $16-$ 22.
Alvar J, Gutiérrez-Solar B, Molina R, López-Vélez R, García-Camacho M, Martínez P, Laguna F, Cercenado E, Galmes A 1992. Prevalence of Leishmania.

Andrade C, Kirchhoff LV, Donelson JE, Otsu K 1992. Recombinant Leishmania $\mathrm{Hsp} 90$ and $\mathrm{Hsp} 70$ are recognized by sera from visceral leishmaniasis patients but not Chagas' disease patients. J Clin Microbiol
30: 330-335.

Badaró R, Jones TC, Carvalho EM, Sampaio D, Reed perspectives, Teixeira R, Johnson WD 1986. New perspectives on a subclinical form of vis
maniasis. J Infect Dis 154: 1003-1011.

Badaró R, Pedral-Sampaio D, Johnson Jr WD, Reed SG 1990. Evaluation of stability of a soluble intradermal skin test antigen preparation in American vis226-227.

Bryceson ADM 1976. Tropical dermatology; Cutane-
ous leishmaniasis. Brit I Dermatol 94: 223-226 Badaro R, Reed SG 1993. Molecular characterization of a kinesin-related antigen of Leishmania chagasi hat detects specific antibody in African and ASA 90: 775-779.

Castés M, Blackwell J, Trujillo D, Formica S, Cabrera M, Zorrilla G, Rodas A, Castellanos PL, Convit J 1994. Immune response in healthy volunteers vaccinated with killed leishmanial promastigotes plus BCG. I: Skin-test reactivity, T-cell proliferation a interferon-gproduction. Vaccine 12. 1041-1051. Elmes BGT, Hall RN 1944. Cutaneous leishmaniasis in
Nigeria Trans $R$ Soc Trop Med Hyg 37: 437-439. Furtado T 1980. Critérios para o diagnóstico leishmaniose tegumentar americana. An Bras
le Dermatol 55: 81-86.

Gradoni L, Gramiccia M, Betti F 1990. Fatal visceral disease caused by a dermotropic Leishmania in a patient with human immunodeficiency virus. $J$ In-

Griffiths WAD 1987. Old World cutaneous leishmaniasis, p. 617-636. In W Peters \& R Killick-Kendrick vol. 2, Clinical Aspects and Control, Academic Press, Inc., New York.

Grimaldi Jr G 1995. Meetings on vaccine studies towards the control of leishmaniasis. Mem Inst Oswaldo Cruz 90: 553-55

Grimaldi Jr G, Tesh RB 1993. Leishmaniasis of the New World: Current concepts and implications for fut renearch. Clin Microbiol Rev 6. 230-250. Haemoflagellates: commercially available liquid 316.

Jaffe CL, Zalis M 1988. Use of purified proteins from Leishmania donovani for the rapid serodiagnosis of vishmania donovani for the rapid serodiagnosis of
Jelliffe RS 1955. Cutaneous leishmaniasis in Nigeria and
the Western Sudan. West Afr Med J 4: 92-94. adaro AY, Ghalib HW, Ali MS, Eltoum I, Ismail A, Gaafar A, Kemp M, Kordofani AAY, Reed SG, ElHassan AM, Kharazmi A, Hag-Ali M, Mustafa MD 1993. Prevalence of cutaneous leishmaniasis along the Nile River north of Khartoum (Sudan) in the af-
termath of an epidemic in 1985. Am J Trop Med Hyg termath of an epidemic in 1985. Am J Trop Med Hyg
48: 44-49.

anson-Bahr PEC 1987. Diagnosis, p.709-729. In W niases in Biology and Medicine, vol. 2, Clinical As pects and Control, Academic Press, Inc., New York. Marty P, Lelievre A, Quaranta J-F, Rahal A, GariToussaint M, Le Fichoux Y 1994. Use of the leishmanin skin test and Western blot analysis for epidemiological studies in visceral leishmaniasis
areas: experience in a highly endemic focus in AlpesMaritimes (France). Trans R Soc Trop Med Hyg 88 . 658-659.

Mayrink W, Costa CA, Magalhães PA, Melo MN, Dias M, Oliveira Lima A, Michalick MS, Williams P 1979. A field trial of a vaccine against American dermal leishmaniasis. Trans $R$ Soc Trop Med Hyg

McCulloch WE 1930. Annual report on the pathological laboratory, Kaduna. Ann Med Sanit Rep, Nigeria, for the year 1929, Appendix, 65 pp.

maniasis diagnosed in Kano, Northern Nigeria. West
maillan B 1957. An unual case of cutaneous leish Afr Med J 6: 190-191.

Modabber F 1990. Development of vaccine against leishmaniasis. Scand J Infect Dis 76 (Suppl.): 72-78. Intern J Dermatol 30: 274-275.
.

Pampiglione S, Manson-Bahr PEC, La Placa M, Borgatti leishmaniasis. 3. The leishmanin skin test in kalaazar. Trans R Soc Trop Med Hyg 69: 60-68.

chaefer KU, Schoone GJ, Gachihi GS, Muller AS, Kager PA, Meredith SEO 1995. Visceral leishmaniasis: use of the polymerase chain reaction in an
epidemiological study in Baringo District, Kenya.

Shreffler WG, Burns JJ, Badaró R, Ghalib HW, Button LL, McMaster WR, Reed SG 1993. Antibody responses of visceral leishmaniasis patients to gp63, a major surface glycoprotein or

Sokal JE 1975. Measurement of delayed skin test responses. New Engl J Med 293: 501-502

Weigle KA, Valderrama L, Arias AL, Santrich C, Saravia NG 1991. Leishmanin skin test standardization and
evaluation of safety, dose, storage, longevity of reaction and sensitization. Am J Trop Med Hyg 44: 260-271.

Zijlstra EE, El-Hassan AM 1993. Leishmanin and tuberculin sensitivity in leihmaniasis in the Sudan, wi special reference to kala-azar. Trans $R$ Soc Trop Med 
